\title{
O PROBLEMA DA AMPLIAÇÃO RECENTE DA UNIVERSIDADE PÚBLICA PAULISTA
}

\section{THE PROBLEM OF RECENT EXPASION OF THE PUBLIC UNIVERSITY OF SÃO PAULO STATE
EL PROBLEMA DE LA RECENTE EXPANSIÓN DE LA UNIVERSIDAD PÚBLICA DEL ESTADO DE SÃO PAULO

Fabrício Ribeiro dos Santos Godoi Mestrando em Arquitetura e urbanismo pelo Instituto de Arquitetura e Urbanismo da Universidade de São Paulo (IAU/USP) fabricio.godoi@usp.br

\begin{abstract}
RESUMO: O objetivo desse artigo é verificar como ocorreu a recente expansão das universidades públicas paulistas (USP, UNESP e UNICAMP), mais especificamente, a relação entre a ampliação física, em relação ao projeto de universidade preferido pelo Governo do Estado e gradualmente implantado pelas gestões reitorais, que suscitou uma suposta crise. Será utilizado o caso da Universidade de São Paulo, no período compreendido entre a promulgação da Lei de Diretrizes e Bases da Educação (1996) e a data atual. Para orientar a análise, é utilizada a proposta de Boaventura de Souza Santos, que identifica a crise global da Universidade em três aspectos principais: uma crise institucional, uma de legitimidade e uma de contradição. Considera-se, ao final, que as universidades públicas paulistas vivem essas crises e sua expansão, de caráter exclusivamente utilitarista, é parte dessas crises.

PALAVRAS-CHAVE: Educação Superior Pública. Crise da Universidade. Expansão da Universidade. Universidade de São Paulo. Universidade Neoliberal.
\end{abstract}

ABSTRACT: The purpose of this article is verify how the recent expansion of the São Paulo state universities (USP, UNESP and UNICAMP) occurred, specifically the relationship between the physical extension in relation to the project of university chosen by the State Government and gradually deployed by rectorals managements, that elicited a supposed crisis. The case of the University of São Paulo will be used, in the period between the enactment of the Law of Guidelines and Bases of Education (1996) until the current date. To guide the analysis it will be used texts by Boaventura de Souza Santos, which identifies the global crisis of the university in three main aspects: an institutional crisis, a legitimacy one and a contradiction one. It is considered, in the end, the São Paulo state universities are living these crises. Its expansion has a exclusively utilitarian character and can be considered part of these crises.

KEYWORDS: Public Higher education. Crisis of the university. Expansion of the university. University of São Paulo. Neoliberal university.

RESUMEN: El propósito de este artículo es comprobar cómo se produjo la reciente expansión de las universidades del estado de São Paulo (USP, UNESP y UNICAMP), específicamente la relación entre la extensión física en relación con el proyecto de universidad elegido por parte del Gobierno del Estado y gradualmente realizado por gestiones rectorales, lo que suscitó una supuesta crisis. Será utilizado el caso de la Universidad de São Paulo, en el período comprendido entre la promulgación de la Ley de Directrices y Bases de la Educación (1996) y la fecha actual. Para guiar el análisis enbasaremos en dos textos de Boaventura de Souza Santos, que identifica a la crisis global de la universidad en tres aspectos principales: una crisis institucional, una de legitimidad y una de contradicción. Se considera que, al final, las universidades del estado de Sao Paulo están sujetas a este tipo de crisis y su expansión, de carácter exclusivamente utilitario, es igualmente parte de estas crisis.

PALABRAS CLAVE: Educación Superior Pública. Crisis de la Universidad. Expansión de la Universidad. Universidad de São Paulo. Universidad Neoliberal. 


\section{1 | ANTECEDENTES, CONTEXTO E PROBLEMA}

O Brasil viveu um período sem democracia de 1964 a 1988, quando uma nova Constituição foi promulgada, depois de construída por um parlamento eleito pelo povo para esse fim. Essa Constituição, conhecida como "Constituição Cidadã”, trouxe a necessidade de uma nova legislação para a área da educação. A Lei de Diretrizes e Bases (LDB) da educação brasileira foi promulgada com essa finalidade, apenas em 1996 (BRASIL, 1996), em substituição à Lei da fase ditatorial de 1971 (BRASIL, 1971), após seis anos de discussões, e apresentada pelo então Senador Darcy Ribeiro. A partir dessa Lei, foi constituída a expansão recente da Universidade pública brasileira e paulista, tema desse texto.

O mesmo Darcy Ribeiro foi um dos idealizadores da Universidade de Brasília e da Lei de Diretrizes e Bases anterior à versão da ditadura de 1961 (BRASIL, 1961). Esses acontecimentos tinham como característica principal a viabilização de um modelo educacional que conduzia ao pensamento sobre os problemas enfrentados pela sociedade brasileira e as melhores maneiras de formar pessoas para a solução desses problemas. No entanto, a ditadura que tomou o poder em 1964 promoveu uma Reforma Universitária (em 1968) que, juntamente com a LDB de 1971, retrocedeu nos avanços democráticos e no arranjo multidisciplinar da educação superior ${ }^{1}$, alterando, principalmente, a organização econômica da educação nacional que passou a ser responsabilidade compartilhada entre um setor público e um setor privado. A expansão universitária, necessária para acomodar a crescente demanda por educação superior, se deu principalmente pelas instituições do setor privado, tanto as confessionais, comunitárias, como as que se arranjam unicamente como empresa capitalista².

ALDBde 1996 não modificouessa estrutura compartilhada, apesar de aperfeiçoaros mecanismos de controle que o Estado brasileiro detém. Essa LDB foi aprovada durante o governo Fernando Henrique Cardoso, marcado por sua ortodoxia no cumprimento das regras, ou, melhor dizendo, das recomendações da política neoliberal. Essa política se caracteriza por ser representativa de uma visão contemporânea de mundo (pós-crise dos anos 70), na qual os movimentos da classe trabalhadora não são mais protagonistas. O bem-estar social conquistado nas décadas anteriores foi desmontado (no caso brasileiro, nem chegou a ser montado integralmente) e vive-se sob uma estagnação econômica permanente tendo, como um pano de fundo, uma versão financeirizada do capitalismo ${ }^{3}$.

Desde a aprovação da LDB em 1996, o Brasil vive um período democrático, com o governo controlado, sucessivamente, por um grupo que defende as políticas liberais (mais precisamente, neoliberais) e outro grupo liderado por um partido - Partido dos Trabalhadores (PT), com origens na esquerda do espectro ideológico, mas comprometido com as mesmas políticas liberais em nome da governabilidade, já que, segundo esse grupo, em um Estado com sistema de presidencialismo de coalizão, não é possível governar sem alianças amplas, que invadem outros campos do espectro ideológico. No entanto, no Estado de São Paulo, o grupo que se perpetua no poder há 32 anos é o mesmo que antes ocupava o governo da União, liderado pelo Partido da Social Democracia Brasileira (PSDB). Portanto é possível assumirmos que a expansão do ensino supe-

\footnotetext{
1Sobre o impacto da reforma universitária, ver o texto de Paula (2001).

${ }^{2}$ Os dados sobre a expansão das instituições privadas, no horizonte desse trabalho, estão compilados e interpretados no livro de Menezes (2000). Sobre a qualidade dessas instituições, recomendamos o texto do prof. Mozart Neves Ramos (2000).

${ }^{3}$ Esse pano de fundo sobre o qual os temas correntes deste trabalho se colocam está muito bem descrito por Moishe Postone (2008), especialmente em sua análise sobre o texto "A condição Pós-Moderna”, de David Harvey.
} 
superior, no Estado de São Paulo, independentemente da origem privada ou pública, ocorreu de maneira submissa a essa política liberal ${ }^{4}$.

Antes da análise dos dados dessa expansão, é prudente pontuar algumas outras características da Universidade contemporânea, sua missão e seu papel na sociedade. Esse texto não pretende resgatar a história da Universidade, mas precisa, minimamente, compreender essa transformação mais recente. No passado, a instituição Universidade era o lócus do debate sobre o conhecimento, de forma multidisciplinar e integrada, frequentada por uma elite intelectual não necessariamente conectada com as elites políticas e econômicas ${ }^{5}$. No Brasil, o ensino superior surgiu fragmentado e especializado, tendo em vista o modelo colonizador português que não procurava estabelecer uma civilização americana no país. Portanto o ideal de multidisciplinaridade e integralidade universitária não esteve presente na origem do ensino superior brasileiro. Somente no início do século passado, as escolas de ensino superior superaram a fragmentação, unindo-se em universidades. A fundação da Universidade de São Paulo (USP), em 1934, é exemplar: reuniramse algumas escolas pré-existentes, principalmente de formação profissional e, para atingir um patamar universitário (no sentido da mencionada integralidade), foi criada uma unidade na qual o fim seria o debate sobre o saber fundamental - a Faculdade de Filosofia, Ciências e Letras (FFCL), atual Faculdade de Filosofia, Letras e Ciências Humanas (FFCLH). Desde sua fundação, esteve comprometida com o tripé ensino, pesquisa e extensão.

Até 1961, antes da primeira LDB, o acesso ao ensino superior acontecia por meio de um exame de admissão, no qual o "desenvolvimento intelectual" do candidato era avaliado de acordo com o Decreto $n^{\circ}$ 8.659, de 5 de abril de 1911 (BRASIL, 1911). Esse exame exigia um grau de conhecimento que a maior parte da população brasileira não atingia, ou ainda, acessível apenas a uma elite econômica que teve educação fundamental de qualidade. $O$ ensino desse período exigia grande erudição e domínio de línguas estrangeiras. A intenção principal do ensino superior era formar a elite dirigente do país. Após 1961, com a ampliação do ensino fundamental no país e o forte crescimento demográfico, a demanda cresceu exponencialmente. A carência de vagas (mesmo considerada a interiorização do ensino) obrigou a criação de um exame vestibular. $O$ perfil do estudante e da própria Universidade também se alterou, já que a industrialização e a urbanização do país exigiam uma classe qualificada para o trabalho. Durante essa expansão, que continuou sob os auspícios da LDB do governo ditatorial, a educação em nível superior era entendida como uma forma de ascensão social.

No entanto, a formação da elite intelectual e da elite dirigente do país também necessitava de um lugar. A USP vinha ocupando esse lugar há décadas, contando com os professores mais renomados, o exame vestibular mais concorrido e o aporte de maiores verbas, dentro de um projeto do governo paulista que, mesmo com eventuais alterações de comando, permaneceu até a promulgação da última LDB ${ }^{6}$.

A expansão do ensino superior continua até o tempo presente, tanto nas instituições públicas (menos) quanto nas instituições privadas (mais). A USP e as demais universidades públicas pau-

\footnotetext{
${ }^{4}$ O texto "Universidade e mercado", de Fábio Camilo Biscalchin (2000), descreve a relação entre o governo do PSDB e a Universidade pública paulista. Mais à frente, o autor explica como a Universidade do PSDB é vinculada ao conceito de "menoridade", de Adorno / Hockheimer e Kant.
}

${ }^{5}$ Sobre a história da Universidade, há diversos textos que merecem ser lidos. A introdução de Universidade Sitiada, de Luís Carlos de Menezes (2000) é um bom resumo crítico, bem como o pequeno livro O que é universidade, de Luís Eduardo Wanderley (1983).

${ }^{6}$ Sobre as três fases da história da USP (a Universidade das elites, a Universidade da ascensão social e a Universidade contemporânea), há o texto da Prof. ${ }^{a}$ Marilena Chauí (1994). 
paulistas tornaram-se instituições de grandíssimo porte, ainda que só detêm aproximadamente $7 \%$ das vagas de ensino superior, em nível de graduação no Estado. É fácil verificar a dimensão dessas universidades: a pesquisa no Brasil cresceu 42\% de 2002 a 2008, enquanto o percentual das públicas paulistas nesse total esteve sempre em torno de 50\% (FAPESP, 2010).

Essas dimensões maiúsculas causaram uma transformação no perfil dessas universidades que hoje ainda formam a elite intelectual e a elite dirigente do país, também fornecem profissionais para o mercado e o setor público. Esse quadro sofre algumas alterações nos últimos dezoito anos. A principal novidade está na forma como a sociedade contemporânea percebe a instituição Universidade: em primeiro lugar, a titulação universitária é vista quase como uma obrigação para almejar-se salários dignos no mercado capitalista; em segundo lugar, a qualidade de uma universidade é avaliada, principalmente, com o uso de métodos comparativos, no mais das vezes quantitativos, inserindo a Universidade (mesmo a pública) em uma lógica de competição capitalista, tipicamente neoliberal, em concordância com o perfil do governo atual ${ }^{7}$. Verificaremos, agora, como a Universidade pública paulista respondeu a essas pressões.

Na tabela 1, veremos a expansão da USP, que será adotada como exemplo, mas a situação é similar nas outras públicas paulistas.

Tabela 1 - Expansão da USP

\begin{tabular}{|c|c|c|c|c|c|c|c|c|c|}
\hline \multirow[b]{2}{*}{ Ano } & \multirow[b]{2}{*}{ Novos Campi } & \multicolumn{8}{|c|}{ Expansão da USP } \\
\hline & & Opç̃es & Vagas & Inscritos & Área constr. & Orçamento & Alunos (grad.+pós) & Docentes & Funcionários \\
\hline 2014 & & 177 & 11157 & 172045 & Indisponivel & 4595,78 (previsto) & Indisponivel & Indisponivel & Indisponivel \\
\hline 2013 & & 173 & 11082 & 159609 & 1915 & $4410,96(4305,56)$ & $58204+29547$ & 6008 & 17450 \\
\hline 2012 & & 172 & 10952 & 146892 & 1821 & $4299,61(3977,11)$ & $58303+28498$ & 5860 & 16839 \\
\hline 2011 & & 166 & 10752 & 132993 & 1778 & $4194,14(3598,44)$ & $57902+27795$ & 5940 & 16512 \\
\hline 2010 & & 171 & 10702 & 126825 & 1757 & $3649,91(2979,62)$ & $57300+26568$ & 5865 & 16187 \\
\hline 2009 & & 167 & 10607 & 138242 & 1739 & $3840,01(2815,99)$ & $56998+25591$ & 5732 & 15341 \\
\hline 2008 & & 161 & 10452 & 140999 & 1722 & $3431,18(2560,01)$ & $55863+25495$ & 5638 & 15438 \\
\hline 2007 & Leste, Lorena & 153 & 10202 & 142656 & 1637 & $3486,82(2369,21)$ & $54361+25443$ & 5434 & 15221 \\
\hline 2006 & & 149 & 9967 & 170474 & 1611 & $3347,64(2111,11)$ & $51980+24836$ & 5358 & 15409 \\
\hline 2005 & São Carlos 2 & 142 & 9567 & 154513 & 1601 & $3234,89(1964,42)$ & $48530+25007$ & 5222 & 15295 \\
\hline 2004 & & 125 & 8587 & 157808 & 1561 & $2945,96(1767,74)$ & $45946+24408$ & 5078 & 15008 \\
\hline 2003 & & 122 & 8331 & 161147 & 1451 & $2867,34(1530,48)$ & $44696+24312$ & 4953 & 14905 \\
\hline 2002 & & 111 & 7805 & 146307 & 1436 & $2860,26(1404,62)$ & $42554+23709$ & 4884 & 14952 \\
\hline 2001 & & 97 & 7354 & 139746 & 1424 & $3249,10(1273,36)$ & $40162+23765$ & 4755 & 14589 \\
\hline 2000 & & 94 & 7395 & 144732 & 1380 & $3306,14(1173,95)$ & $39326+22774$ & 4694 & 14184 \\
\hline 1999 & & 95 & 7076 & 123685 & 1367 & $2842,73(918,04)$ & $39155+22570$ & 4728 & 14186 \\
\hline 1998 & & 124 & 6921 & 126184 & 1367 & $3188,32(842,25)$ & $33934+21009$ & 4705 & 14659 \\
\hline 1997 & & 123 & 6877 & 116903 & 1316 & $3619,25(887,41)$ & $33020+19713$ & 4852 & 14699 \\
\hline Fontes & 1 & 2 & & 4 & 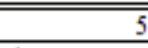 & & 7 & & \\
\hline 1 & \multicolumn{9}{|c|}{ Dados retirados dos sitios de internet das unidades acadèmicas. } \\
\hline 2 & \multicolumn{9}{|c|}{ Opyões de cursos (não é igual ao total de cursos oferecidos). Dados FUVEST (Nota: até 1998, o vestibular de Letras era sepparado para cada habilitação). } \\
\hline 3,4 & \multicolumn{9}{|c|}{ Dados FUVEST (Para evitar distorções, foram excluidos os inscritos nas instituições federais, mas foram mantidos os candidatos a treinciros e Acadeppol). } \\
\hline 5 & \multicolumn{9}{|c|}{ Dados do Anuário Estatístico (em milhares de m2). } \\
\hline 6 & \multicolumn{9}{|c|}{ Dados da Coordenadoria de Administração Geral (CODAGE), corrigidos segundo o indice IGP-M, em milhões de reais (entre parènteses o valor absoluto). } \\
\hline 7 & \multicolumn{9}{|c|}{ Dados do Anuário Estatístico (Nota: em 1989, havia 5626 docentes, 17735 funcionários não docentes, 31.897 alunos da graduação e 12914 alunos da pós). } \\
\hline
\end{tabular}

Fonte: Tabela elaborada pelo autor.

${ }^{7}$ Sobre a avaliação e o produtivismo quantitativo, ver Bosi (2000). Uma avaliação mais detalhada está no livro "Universidade desconstruída", organizado por José Dias Sobrinho e Dilvo I. Ristoff (2000). 
Depreendemos pela tabela que, nos últimos 18 anos, as vagas cresceram $62 \%$, enquanto o número de alunos de graduação na USP, por exemplo, aumentou em mais de $76 \%$ e da pós-graduação, em quase $50 \%$. O número de docentes aumentou $23,8 \%$ e o de funcionários, $18,7 \%$. A área construída cresceu 45,5\%. A relação de alunos para cada docente passou de 10,8 para 14,5. Finalmente, a arrecadação passou de 0,88 bilhão (1997) para 4,6 bilhões (2014), em valores reajustados. O acréscimo é de $26,9 \%$, sendo que os valores de 1997 foram recuperados há somente três anos.

Há decorrências óbvias, como: a nítida sobrecarga de trabalho dos docentes, que lidam com um universo maior de alunos; o crescimento da área física é insuficiente para a população atual (e a complexidade, já que há cursos e campi novos); o orçamento não acompanhou o crescimento da instituição. Há outras constatações menos óbvias, cujas subjetividades não permitem que as conclusões sejam formuladas apenas por uma análise direta de dados tabulados.

A seguir, serão apresentadas algumas características do modelo de Universidade que o governo do Estado vem construindo, a despeito das limitações que as idiossincrasias da autonomia universitária ainda conseguem interpor.

\section{2 | A UNIVERSIDADE CONTEMPORÂNEA E A CRISE NEOLIBERAL}

As universidades de todo o mundo sofreram, desde o advento da produção em massa, alterações em seu papel fundamental. Na história recente da humanidade, a construção do "indivíduo-empresa" (que possui necessidade de sucesso) o empurra para a exigência de formação profissional altamente qualificada ${ }^{8}$. A princípio, na indústria, mas depois, em todas as áreas da atividade humana, foi papel delegado às universidades. Daí surgem as três crises que Boaventura de Souza Santos $(1989,2010)$ pontua em dois textos ${ }^{9}$, a saber:

a) uma crise de natureza institucional, relacionada à autonomia universitária, que tem origem na necessária independência financeira da Universidade pública. Essa desejável independência vem sendo subtraída seguidamente, já que há instituições privadas que oferecem o mesmo "produto" desejado pela sociedade para o desenvolvimento individual do cidadão: a qualificação profissional. Em segundo lugar, pela vinculação da pesquisa desenvolvida na Universidade aos interesses das empresas privadas, que assim podem injetar verbas na primeira. Essas condições ocorrem também em todos os outros campos em que o Estado atua, devido à premissa neoliberal do "Estado Mínimo", liberando atividades antes exclusivamente estatais para a iniciativa privada. Outra face desse processo é a transnacionalização da educação superior, com a criação e ampliação de grandes conglomerados universitários, mais "eficazes" e "ágeis" para adequar sua oferta às necessidades do capitalismo contemporâneo. É importante dizer que a educação é um negócio, nos números do Banco Mundial apresentados no texto referenciado de 2004, duas vezes maior que o mercado automobilístico. O auge dessas transformações é a percepção de que a Universidade (pública ou privada) é uma instituição que oferece um serviço como qualquer outro, devendo ser regida pelas leis do mercado, compreendida como uma "empresa". Nesse momento, que talvez ainda não tenha sido atingido (tanto na

\footnotetext{
${ }^{8}$ Laval e Dardot (2013) explicam como se dá o surgimento desse indivíduo-empresa, como é o "governo" desse sujeito e como a subjetividade dessa construção o estimula, por exemplo, para essa formação profissional qualificada e para a repetição contínua desses processos alienantes, o afastando, consequentemente, da emancipação.

${ }^{9}$ Em 1997, com o texto "Da ideia de universidade à universidade de ideias" e em 2004, com o texto "A universidade do século XXI: para uma reforma democrática e emancipatória da universidade".
} 
época que o autor escreve, em 2004, como hoje), não faria sentido diferenciar a Universidade pública da privada, tornando-se essa uma questão puramente retórica;

b) a segunda crise seria uma crise de legitimidade, que é vinculada à primeira, mas não causada apenas pelos mesmos motivos. Essa crise de legitimidade ocorre devido às pressões da sociedade, no sentido de democratizar o acesso ao ensino superior, com a universalização, por exemplo. Esse acesso é impossibilitado tanto pela inexistência de vagas para todos, como pelos critérios de seleção (credenciamento de competências), necessários à manutenção da hierarquização dos saberes especializados. Dessa forma, desaparece o consenso sobre a efetividade da Universidade como lócus dessa universalização;

c) a terceira crise é igualmente decorrente da primeira e trata-se de uma crise contraditória entre a autonomia universitária, que preconiza a decisão sobre os deveres e objetivos da Universidade, e as pressões da sociedade (induzidas pelo mercado e pela necessidade contemporânea de consumo) por uma instituição mais eficaz e produtiva, sob uma análise com critérios empresariais.

Para explicar como essa primeira crise se apresenta no Brasil, apresentaremos alguns dados a seguir. Em nosso país, a relação de vagas entre instituições privadas e públicas é de $73,55 \%{ }^{10}$. Até meados dos anos setenta, a disputa ideológica se fazia entre as universidades públicas e as confessionais, gerando uma tensão até hoje distante de ser superada ${ }^{11}$. Desde então, as universidades empresariais se ampliaram ao sabor da demanda do mercado, com frouxo controle estatal. No Estado de São Paulo, as três universidades públicas também cresceram consideravelmente (os números apresentados anteriormente são exemplares), mas muito abaixo do índice de crescimento das instituições privadas. Atualmente, as matrículas das universidades públicas computam aproximados $15,9 \%$ do total, sendo aproximadamente $10,5 \%$ nas estaduais ${ }^{12}$.

O financiamento das universidades públicas paulistas é composto, principalmente, por repasses de um percentual do Imposto sobre Circulação de Mercadorias e Serviços (ICMS), cuja arrecadação é diretamente relacionada com o consumo. O percentual mínimo fixado em Decreto de 1989 é de 8,4\%, mas desde 1995 está fixado em 9,57\%, a despeito do crescimento previamente apresentado ${ }^{13}$. Ou seja, a arrecadação flutua anualmente ao sabor da "economia de mercado", e os recentes recordes orçamentários são puro reflexo de um momento histórico no qual o consumo e a economia interna do país estão em relativa alta.

Esses mesmos dados permitem avaliarmos como a segunda crise se impõe no Brasil. Mais uma vez, como exemplo, observa-se que a Universidade pública paulista de fato apresentou um crescimento numérico, mas insuficiente para acompanhar o crescimento da demanda criada pelo modelo de Universidade proposto pela mais recente LDB. A transformação da Universidade em lócus da formação técnica de maior complexidade força a citada universalização, que no Brasil ainda está muito distante (em países centrais há índices acima de $90 \%$, a Argentina está acima de $60 \%$ e o Brasil está em 25,5\%) (INSTITUTO NACIONAL DE ESTUDOS E PESQUISAS EDUCACIONAIS

\footnotetext{
${ }^{10}$ Dados do Instituto Nacional de Estudos e Pesquisas Educacionais Anísio Teixeira (2013).

${ }^{11}$ Sobre o histórico da expansão das instituições privadas no Brasil e a origem desse processo, ver Carlos Bauer (2010), que contém o texto "Do Ensino Superior: aspectos de sua história no Brasil".

${ }^{12}$ Dados do Instituto Nacional de Estudos e Pesquisas Educacionais Anísio Teixeira (2013).

${ }^{13}$ Sobre o histórico recente do financiamento das universidades públicas paulistas e a luta para o aumento dos repasses, com manutenção da autonomia universitária para manejo do orçamento, está bem descrita no livro organizado por Álvaro Bianchi (2008a), no texto "Autonomia universitária como projeto".
} 
ANÍSIO TEIXEIRA, 2007).

Além de insuficiente, é fácil observar que o crescimento de matrículas se realizou sem a contraparte em espaço físico, infraestrutura e pessoal. Mais ainda, é possível avaliarmos que essa expansão é baseada em um processo de degradação institucional. As verbas orçamentárias não acompanham o crescimento populacional e são distribuídas ou de acordo com indicadores de produção, ou de acordo com os interesses das agências financiadoras de pesquisas, que se vinculam ao Governo do Estado por meio de outra Secretaria. Nesse caso, as áreas consideradas "operacionais" recebem maior investimento, em detrimento das áreas de pesquisa básica ou geral (como as humanidades). A pesquisa "operacional", ligada à aplicação produtiva empresarial, é flagrantemente privilegiada ${ }^{14}$. Portanto a luta dos grupos defensores do pensamento livre na Universidade é contra esse perfil operacional da pesquisa e da formação técnica, que a coloca a serviço da produção capitalista. Considerando os dados recentes, a crise de legitimidade está posta: essa luta aparentemente está sendo perdida ${ }^{15}$.

Finalmente, com relação à terceira crise, a contradição entre a autonomia universitária e a pressão da sociedade é notável, por exemplo, observando-se a reação da mídia aos conflitos internos da Universidade. Na atual greve (ainda em curso), há uma campanha praticamente aberta do jornal "Folha de São Paulo", para que a Universidade de São Paulo adote estratégias empresariais e passe a efetuar a cobrança de mensalidades para os alunos que tenham condições de pagá-la ${ }^{16}$.

A sociedade, influenciada por essas campanhas midiáticas, exige resultados quantitativos da Universidade, mensuráveis via número de vagas no vestibular, ou por índices internacionais de qualidade - que também utilizam critérios quantitativos. E a administração da Universidade persegue esses índices ${ }^{17}$.

\section{3 | O CRESCIMENTO DA INFRAESTRUTURA NA USP E A CRISE}

Conforme visto na tabela 1, a área construída da USP cresceu 45,5\% nos últimos 18 anos, sendo que somente no ano de 2013 o índice foi de 7,1\%. Estão em curso obras que acrescentarão mais $153.000 \mathrm{~m} 2$, ou $8 \%$ com relação à área atual. O valor total investido nessas obras ainda não entregues é maior que 683,5 milhões de reais. Toda essa expansão do espaço físico é composta por obras iniciadas na última gestão reitoral, marcada por fortes despesas em obras e pela recurecuperação do quadro funcional, em termos numéricos e de valorização salarial18.

Considerando as crises da Universidade citadas anteriormente, qual a relação que podemos

\footnotetext{
${ }^{14}$ No mesmo texto da nota 3, o autor apresenta dados a respeito.

${ }^{15} \mathrm{Em} \mathrm{2007,} 2010$ e 2013 aconteceram greves nas universidades estaduais (e no momento de construção desse texto, há outra greve em curso). Em todas elas, a questão da privatização esteve em pauta. Em alguns casos, de forma muito explícita, cogitando-se, inclusive, a possibilidade de cobrança de mensalidades. Sobre a greve atual, ver o texto do prof. Jorge Souto Maior (2014); sobre a crise de 2013, ver o texto "Democracia na USP", do prof. Vladimir Safatle (2013); sobre a greve de 2010, ver o texto "A destruição dos quadros técnicos e administrativos nas universidades paulistas", do prof. Luiz Carlos de Freitas (2010) e, finalmente, sobre a greve e a ocupação de 2007, ver o texto postado por Silva (2007) que contém o texto com as reivindicações dos estudantes, entre as quais destacamos a primeira, que foi repetidamente posta em pauta nas greves subsequentes.

${ }^{16}$ Apenas a título de exemplo, há um texto de Fraga e Takahashi (2014), que calcula valores possíveis para as mensalidades.

${ }^{17}$ A Reitora que comandava a USP, durante a greve de 2007, escreveu o texto "USP: uma universidade de classe mundial”, no qual constrói sua proposta a partir de rankings. (UNIVERSIDADE DE SÃO PAULO, 2007).
} 


\section{fazer com essa expansão?}

Serão apresentados alguns dados que podem auxiliar na resposta dessa questão, além de algumas conjecturas ou especulações a respeito.

Com relação à crise institucional, os primeiros aspectos a relevar são sobre a autonomia universitária e a independência financeira. Por um lado, essas condições permitem que a decisão sobre onde aplicar o orçamento seja prerrogativa da gestão reitoral, que submete a proposta orçamentária para o Conselho Universitário. Esse procedimento permite que a própria Universidade decida quais áreas do conhecimento vão receber maiores investimentos, por exemplo. Por outro lado, são condições que permitem ao Governo Estadual eximir-se da responsabilidade de aplicar outras verbas na Universidade, que não os repasses do Tesouro Estadual, devidamente votados pela Assembleia Legislativa de São Paulo (os citados 9,57\%). Essa isenção do Governo Estadual não o impede de interferir politicamente nas decisões sobre quais áreas do conhecimento serão privilegiadas.

É mais fácil entender como o Governo Estadual interfere na gestão reitoral, mesmo sem aplicar verbas adicionais na Universidade, analisando o processo de escolha do Reitor. Na USP, o cargo máximo é escolhido pelo próprio Governador, a partir de uma lista tríplice que é composta pelos três professores titulares (nível hierárquico máximo na carreira) mais votados em eleição com Colégio Eleitoral muito reduzido (na última eleição, o Colégio ampliou-se de aproximadamente 300 votantes para 2000). Até a última eleição, não havia a formação de candidaturas formais. Portanto havia (e ainda há) uma política exercida por poucos indivíduos, sujeita a muitas falhas democráticas, como a priorização de interesses individuais ou a simples troca de favores.

Essas condições conduzem, também, a uma centralização decisória, exercida por alguns reitores de forma até autoritária. Para exemplificar, a greve atual da Universidade é resultado direto dessa centralização de poder. A última gestão reitoral que, como afirmado anteriormente, investiu na recuperação dos quadros funcionais e um alto valor em obras, se caracterizou pela pouca transparência e por, supostamente, não submeter suas decisões ao Conselho Universitário ${ }^{19}$. Essa situação levou a Universidade ao comprometimento com a folha salarial em uma porcentagem acima dos repasses do Tesouro Estadual ${ }^{20}$.

A situação financeira precária, ou pelo menos a emergência midiática dessa precariedade, leva à busca de outras fontes de financiamento para a Universidade pública, que não sejam os repasses diretos do Estado. A decisão institucional ${ }^{21}$ em realizar essa busca pode comprometer a liberdade de pesquisa, em primeiro lugar, mas também o ensino. É fácil constatar nas unidades que já detêm maior quantidade de pesquisas operacionais, pela própria natureza da área, que as empresas privadas já financiam o pagamento de pesquisadores estagiários, ou mesmo realizam parcerias nas quais a empresa paga as despesas com a pesquisa, enquanto a instituição usa seu know-how e seu pessoal (BIANCHI, 2008b). Por exemplo, as empresas transferem a prática de

\footnotetext{
${ }^{18}$ Dados sobre construções em curso e respectivos valores adquiridos pela Superintendência do Espaço Físico (SEF), órgão da USP responsável pelo planejamento do espaço físico. Sobre a recuperação salarial, dado adquirido junto a funcionários da Universidade.

${ }^{19} \mathrm{O}$ atual Reitor afirma o Conselho em entrevista (ZAGO, 2014).

${ }^{20}$ Dados de orçamentos e despesas da USP disponibilizados pela Vice-Reitoria de Administração (UNIVESIDADE DE SÃO PAULO, 2014b).

${ }^{21} \mathrm{~A}$ Comissão de Planejamento composta na comemoração de 75 anos da USP realizou um trabalho com o objetivo de refletir sobre os próximos 25 anos da instituição, nos quais foram traçadas metas, entre as quais diversificar as fontes de financiamento da Universidade (MARQUES, 2008).
} 
pesquisa e desenvolvimento de suas dependências para as dependências da Universidade, depois recebem os royalties compartilhados sobre as patentes. Ganham, com isso, a riqueza do ambiente universitário, livram-se da imobilização do patrimônio, despesas trabalhistas etc. Outro exemplo é a submissão de todas as pesquisas individuais dos ingressantes em programas de pós-graduação necessariamente se vincularem a uma pesquisa maior com visível interesse mercadológico (e em casos mais extremos até vinculados a uma empresa específica). Um exemplo real que foi divulgado com grande regozijo por ambas as partes foi a assinatura de um convênio formal entre a Microsoft e a Universidade de São Paulo, para a criação de um chamado Centro de Estudos de Tecnologia e Sociedade, com a aplicação de 720 mil dólares por parte da empresa (MICROSOFT, 2014; UNIVERSIDADE DE SÃO PAULO, 2013).

A despeito de a notícia publicada prever "total independência", já que seria coordenada pela USP, não há qualquer garantia que seus "produtos" efetivamente sejam utilizados pela empresa, ou que os formandos não sejam treinados com o objetivo específico de posteriormente serem contratados pela empresa. Outro exemplo das transferências são as spin-offs acadêmicas, empresas criadas pela transferência de conhecimento e tecnologia gerados na Universidade (TERRA, 2001). Há também o caso do Parque Tecnológico de Ribeirão Preto (tratado mais adiante nesse texto). É possível denominar essa prática de "privatização por dentro".

Outro aspecto da crise institucional é relativo à "concorrência" com as universidades privadas. Estas conseguem se adequar rapidamente para suprir demandas do "mercado", ou seja, formar rapidamente profissionais qualificados de determinada função, em determinado lugar. Para cumprir essa função de "mercado", algumas instituições públicas se adaptam com a criação de um campus ou unidade com essa função específica, ou, na esfera federal, com a criação de Institutos Tecnológicos. No caso da USP, a resposta foi criar um campus novo, na zona leste de São Paulo, e ali instalar uma nova unidade, a Escola de Artes, Ciências e Humanidades (EACH). Nessa unidade, foram instaladas mais de mil vagas em cursos de nível tecnológico, nas três grandes áreas do conhecimento, com formação em oito semestres e aulas em período parcial (apenas matutino, vespertino ou noturno $)^{22}$. Entretanto, a implantação da chamada USP Leste não é apenas um reflexo da crise institucional; é, principalmente, um reflexo da crise de legitimidade. A pressão da sociedade para a ampliação da Universidade pública só pode ser respondida em grande quantidade e de maneira rápida, assumindo-se a mesma estratégia das empresas privadas de ensino superior, simultaneamente precarizando o ensino, desvinculando-o da pesquisa e extensão e formando em menos tempo, com menor carga horária.

Ainda sobre a crise de legitimidade, as pressões para a ampliação da Universidade pública foram respondidas com o aumento do número de cursos e vagas apresentado na tabela 1. Para responder a esse aumento, diversas obras físicas foram e estão sendo realizadas. A tabela 2 apresenta os valores investidos em obras em execução, nos anos de 2013 e 2014, para cada unidade da USP. Alguns contratos não são vinculados a unidades, por esse motivo o somatório não é igual ao total. Individualmente, os maiores receptores foram obras ligadas à Reitoria. Os contratos de substituição dos sistemas de iluminação pública (quase cem milhões de reais), os destinados aos museus (mais de 124 milhões de reais), construção do Centro de Convenções (quase 105 milhões de reais), edifício para órgãos da reitoria na Rua da Consolação (quase 74 milhões de reais), segunda etapa do Centro de Difusão Internacional (48 milhões de reais), segunda etapa do prédio da Reitoria (quase 26 milhões de reais), todos apresentam valores muito superiores aos destinados para alguma unidade de ensino, no período.

${ }^{22}$ O Curso de Obstetrícia é a exceção: é realizado em nove semestres em período integral. 
O PROBLEMA DA AMPLIAÇÃO | Fabrício Ribeiro dos Santos Godoi

Tabela 2 - Verbas destinadas a obras em execução em 2014

\begin{tabular}{|c|c|}
\hline Unidade & Valor \\
\hline FOB & $\mathrm{R} \$ 6.234 .027,00$ \\
\hline $\begin{array}{l}\text { FMRP } \\
\end{array}$ & $\mathrm{R} \$ 2.143 .839,00$ \\
\hline EEFERP & $\mathrm{R} \$ 364.856,00$ \\
\hline FCFRP & $\mathrm{R} \$ 941.558,00$ \\
\hline FORP & $\mathrm{R} \$ 95.807,00$ \\
\hline FCF & $\mathrm{R} \$ 6.032 .228,00$ \\
\hline FM & $\mathrm{R} \$ 12.760 .708,00$ \\
\hline FSP & $\mathrm{R} \$ 331.052,00$ \\
\hline IB & $\mathrm{R} \$ 4.488 .403,00$ \\
\hline EEFE & $\mathrm{R} \$ 1.892 .594,00$ \\
\hline FO & $\mathrm{R} \$ 656.808,00$ \\
\hline ICB & $\mathrm{R} \$ 1.585 .614,00$ \\
\hline ESALQ & $\mathrm{R} \$ 10.265 .643,00$ \\
\hline FZEA & $\mathrm{R} \$ 5.790 .276,00$ \\
\hline FMVZ & $\mathrm{R} \$ 7.798 .418,00$ \\
\hline EEL & $R \$ 6.294 .556,00$ \\
\hline Pq Tecn RP & $\mathrm{R} \$ 14.560 .503,00$ \\
\hline EESC & $\mathrm{R} \$ 2.849 .200,00$ \\
\hline ICMC & $\mathrm{R} \$ 111.000,00$ \\
\hline IFSC & $R \$ 3.767 .900,00$ \\
\hline Poli & $R \$ 6.621 .232,00$ \\
\hline IME & $\mathrm{R} \$ 869.570,00$ \\
\hline IQ & $\mathrm{R} \$ 608.132,00$ \\
\hline 10 & $\mathrm{R} \$ 1.756 .272,00$ \\
\hline FFCLRP & $\mathrm{R} \$ 1.049 .834,00$ \\
\hline FEARP & $\mathrm{R} \$ 2.660 .880,00$ \\
\hline $\mathrm{EACH}$ & $R \$ 1.755 .000,00$ \\
\hline FD & $R \$ 2.073 .668,00$ \\
\hline $\mathrm{FE}$ & $\mathrm{R} \$ 1.314 .876,00$ \\
\hline FFLCH & $\mathrm{R} \$ 326.829,00$ \\
\hline ECA & $R \$ 0,00$ \\
\hline $\mathrm{EE}$ & $R \$ 0,00$ \\
\hline EERP & $R \$ 0,00$ \\
\hline IAG & $R \$ 0,00$ \\
\hline IAU & $R \$ 0,00$ \\
\hline IF & $\mathrm{R} \$ 0,00$ \\
\hline IGc & $R \$ 0,00$ \\
\hline IMT & $R \$ 0,00$ \\
\hline FAU & $\mathrm{R} \$ 0,00$ \\
\hline IEE & $R \$ 0,00$ \\
\hline IP & $R \$ 0,00$ \\
\hline FDRP & $R \$ 0,00$ \\
\hline IQSC & $\mathrm{R} \$ 0,00$ \\
\hline
\end{tabular}

Fonte: Dados da Superintendência do Espaço Físico (SEF) da USP. 
Ainda sobre a crise de legitimidade, as pressões para a ampliação da Universidade pública foram respondidas com o aumento do número de cursos e vagas apresentado na tabela 1. Para responder a esse aumento, diversas obras físicas foram e estão sendo realizadas. A tabela 2 apresenta os valores investidos em obras em execução, nos anos de 2013 e 2014, para cada unidade da USP. Alguns contratos não são vinculados a unidades, por esse motivo o somatório não é igual ao total. Individualmente, os maiores receptores foram obras ligadas à Reitoria. Os contratos de substituição dos sistemas de iluminação pública (quase cem milhões de reais), os destinados aos museus (mais de 124 milhões de reais), construção do Centro de Convenções (quase 105 milhões de reais), edifício para órgãos da reitoria na Rua da Consolação (quase 74 milhões de reais), segunda etapa do Centro de Difusão Internacional (48 milhões de reais), segunda etapa do prédio da Reitoria (quase 26 milhões de reais), todos apresentam valores muito superiores aos destinados para alguma unidade de ensino, no período.

Algumas dessas obras nada têm a ver com a expansão de cursos e vagas, como o Centro de Convenções e o Centro de Difusão Internacional. Ao contrário, são obras cuja finalidade é mais ligada ao processo de privatização e venda de serviços oferecidos pela Universidade.

Também é notável o investimento realizado pela USP para a construção do Parque Tecnológico de Ribeirão Preto. Além de ceder o terreno no qual foram construídos os edifícios que compõem o referido Parque, a Universidade investiu boa parte dos mais de 14 milhões de reais para sua construção. Esse Parque é um espaço que será gerido por uma Fundação municipal ${ }^{23}$ daquela cidade e conta com uma incubadora de empresas "de base tecnológica", com a oferta de área para produção e infraestrutura administrativa. Conta, também, com espaço para instalação da área de pesquisa e desenvolvimento de empresas que atuam com tecnologia, e até áreas produtivas para essas empresas.

Entre as unidades de ensino, é notável o pequeno investimento nas unidades de humanidades. Enquanto as unidades de Ciências Biológicas receberam mais de 37 milhões e as unidades de Engenharias e Agrárias receberam mais de 45 milhões, as unidades de Ciências Sociais aplicadas receberam menos de 7 milhões e as unidades de Humanidades menos de 2 milhões de reais. As pesquisas operacionais se concentram na área de Ciências Biológicas (desenvolvimento de fármacos e procedimentos na área da saúde humana e animal), Engenharias (desenvolvimento de patentes ligadas a produtos tecnológicos) e Ciências Agrárias (desenvolvimento de insumos e tecnologias ligadas à produtividade e controle da produção).

\section{4 | CONSIDERAÇÕES FINAIS}

Esse texto se soma a diversos outros, no sentido de identificar a real crise da Universidade contemporânea em expansão, com foco no caso brasileiro e mais especificamente na Universidade de São Paulo. A forte expansão da Universidade brasileira a inseriu nesta crise, cujo real sentido não é financeiro-orçamentário ou gerencial, apesar de incluir aspectos dessa ordem. A crise atual é institucional e de legitimidade, como afirma Boaventura de Souza Santos. Mas também e, principalmente, é a crise da contradição.

Essa contradição entre o papel original da Universidade e o papel assumido atualmente surge e se amplia com a submissão da instituição Universidade à racionalidade do capitalismo, de matriz weberiana, com o utilitarismo das instituições e dos saberes e, no nosso entendimento, a falta de interesse pelo pensamento livre - que certamente é contrário ao poder centralizador decorrente dessa racionalização típica desse modo de produção. A expansão da Universidade, inclusive a expansão física, está a serviço desse utilitarismo.

${ }^{23}$ Dados sobre o Parque Tecnológico foram retirados do sítio da Fundação Instituto Polo Avançado da Saúde (2010). 


\section{Referências}

BAUER, C. A classe operária vai ao campus. São Paulo: Sundermann, 2010.

BIANCHI, A. Autonomia universitária como projeto. In: (Org.). Transgressões: as ocupações de Reitoria e a crise das universidades públicas. São Paulo: Sundermann, 2008a.

רาר. O que é a pesquisa operacional? In:

(Org.). Transgressões: as ocupações de Reitoria e a crise das universidades públicas. São Paulo: Sundermann, 2008b.

BISCALCHIN, F. C. Universidade e mercado. In: Papagaios burros. Piracicaba: Biscalchin,

2000 .

BOSI, A. A universidade pública brasileira: perfil e acesso. Cadernos Adenauer, São Paulo, v. 6, ago. 2000.

BRASIL. Decreto-lei n 8.659, de 5 de abril de 1911. Approva a lei organica do ensino superior e do fundamental na Republica. Diário Oficial da União. Brasília, DF, 6 abr. 1911.

BRASIL. Lei n 9.394, de 20 de dezembro de 1996. Estabelece as diretrizes e bases da educação nacional. Diário Oficial da União. Brasília, DF, 23 dez. 1996.

BRASIL. Lei $n^{\circ}$ 5.692, de 11 de agosto de 1971. Fixa diretrizes e bases para o ensino de $1^{\circ}$ e $2^{\circ}$ graus, e dá outras providências. Diário Oficial da União. Brasília, DF, 12 ago. 1971.

BRASIL. Lei $n^{\circ}$ 4.024, de 20 de dezembro de 1961. Fixa as diretrizes e bases da educação nacional. Diário Oficial da União. Brasília, DF, 27 dez. 1961.

CHAUÍ, M. USP 94: a terceira fundação. Estudos Avançados, São Paulo, v. 8, n. 22, set./dez. 1994.

DIAS SOBRINHO, J.; RISTOFF, D. I. (Org.). Universidade desconstruída: avaliação institucional e resistência. Florianópolis: Insular, 2000.

FRAGA, Érica; TAKAHASHI, Fábio. Mensalidade na USP poderia ser paga por $60 \%$ dos alunos.

Folha de São Paulo, São Paulo, 2 jun. 2014. Disponível em: <http://www1.folha.uol.com.br/educacao/2014/06/1463535-mensalidade-na-usp-poderiaser-paga-por-60-dos-alunos.shtml>. Acesso em: 30 jul. 2014.

FREITAS, Luiz Carlos de. A destruição dos quadros técnicos e administrativos nas universidades paulistas. 2010. Disponível em: <http://www.dceunicamp.org.br/ campanhaunificada/?p=32>. Acesso em: 21 out. 2014.
FUNDAÇÃO DE AMPARO À PESQUISA DO ESTADO DE SÃO PAULO. Indicadores de ciência, tecnologia e inovação 2010: relatório. São Paulo, 2010. v. 1.

\section{FUNDAÇÃO INSTITUTO PÓLO AVANÇADO DA}

SAÚDE. Dados sobre o Parque Tecnológico retirados do sítio da Fundação na internet. Ribeirão Preto, 2014. <http://www.fipase.org.br/index.php?option=com_content\&view=article\&id=4\&ltemid=13>. Acesso em: 30 jul. 2014.

INSTITUTO NACIONAL DE ESTUDOS E PESQUISAS EDUCACIONAIS ANÍSIO TEIXEIRA. Sinopse estatística do censo da Educação Superior: sinopse estatística, de 1998 a 2006. Brasília, DF: INEP/MEC, 2007.

Divulgação do censo superior 2013: tabela. Brasília, DF, 2013. Disponível em: <http://download. inep.gov.br/educacao_superior/censo_superior/documentos/2014/principais_resultados_censo_2013.xls>. Acesso: 21 out. 2014.

LAVAL, C.; DARDOT, P. La nueva razón del mundo. Valencia: Gedisa, 2013

MAIOR, Jorge Souto. Democratização vs. privatização da USP: a cartada final. São Paulo, 2014. Disponível em: <http://blogdaboitempo.com.br/2014/05/28/democratizacao-vs-privatizacao-da-usp-a-cartada-final/>. Acesso em: 30 jul. 2014.

MARQUES, F. A USP do futuro. Pesquisa Fapesp, São Paulo, n. 152, p. 37, out. 2008.

MENEZES, L. C. Universidade sitiada. São Paulo: Perseu Abramo, 2000.

MICROSOFT. Pesquisa de tecnologia e sociedade com a USP. São Paulo, 2014. Disponível em: <http:// www.microsoft.com/pt-br/about/impacto-no-brasil/educacao-e-capacitacao/iniciativas/pesquisa-de-tecnologia-e-sociedade-com-a-usp.aspx>. Acesso em: 30 jul. 2014.

PAULA, M. de F. C. de. A inserção da universidade na lógica racionalizadora do capital: casos USP e UFRJ. In: SILVA, W. C. (Org.). Universidade e sociedade no Brasil: oposição propositiva ao neoliberalismo na educação superior. Niterói: Intertexto, 2001.

POSTONE, M. Teorizando o mundo contemporâneo. Novos Estudos, São Paulo, n. 8, jul. 2008.

RAMOS, M. N. Ensino Superior no Brasil: expansão e avaliação do sistema universitário. Cadernos Adenauer, São Paulo, v. 6, ago. 2000. 


\section{Referências}

SAFATLE, Vladimir. Democracia na USP. Folha de São Paulo, São Paulo, 8 out. 2013. Disponível em: <http://www1.folha.uol.com.br/colunas/vladimirsafatle/2013/10/1353197-democracia-na-usp.shtml>. Acesso em: 30 jul. 2014.

SANTOS, B. de S. Da ideia de universidade à universidade de ideias. Revista Crítica de Ciências Sociais, Coimbra, n. 27/28, p. 11-62, jun. 1989.

A universidade do século XXI: para uma reforma democrática e emancipatória da universidade. São Paulo: Cortez, 2010.

SILVA, Edivaldo Lopes Alves da. As 18 reivindicações dos estudantes da ocupação da USP. 2007. Disponível em: <http://arquivoocupa.blogspot.com.br/search/label/As\%2018\%20reivindica\%C3\%A7\%C3\%B5es\%20dos\%20estudantes $\% 20$ da\%200cupa\%C3\%A7\%C3\%A30\%20da\%20USP>. Acesso: 30 jul.2014.

TERRA, B. A transferência de tecnologia em universidades empreendedoras: um caminho para a inovação tecnológica. Rio de Janeiro: Qualitymark, 2001.

UNIVERSIDADE DE SÃO PAULO. Anuário estatístico. São Paulo, 1989-2013. (Edições entre 1989 e 2013). Disponível em: <https://uspdigital.usp.br/anuario/AnuarioControle>. Acesso em: 10 maio 2014.

Coordenadoria de Administração Geral da USP. Informações financeiras para o Conselho Universitário. São Paulo, 2014a. Disponível em: <http://www. vrea.usp.br/?q=node/5>. Acesso: 30 jul. 2014.
Reitoria. USP 2034: planejando o futuro. São Paulo: EDUSP, 2007.

Sala de Imprensa. USP e Microsoft firmam convênio para criação de Centro de Estudos de Tecnologia. São Paulo, 2013. Disponível em:<http://www.usp. br/imprensa/?p=35462>. Acesso em: 30 jul. 2014.

Vice-Reitoria de Administração. USP - transferências do tesouro do Estado em 2014. São Paulo, 2014b. Disponível em: <http://www.vrea.usp.br/files/ CO_2014/execucao_abr14.pdf>. Acesso em: 30 jul. $201 \overline{4}$.

VILELA, S. USP: uma universidade de classe mundial no qual constrói sua proposta a partir de rankings. In: VILELA, S.; LAJOLO, F. M. (Org.). USP 2034: planejando o futuro. São Paulo: EDUSP, 2009.

ZAGO, Marco Antonio. São $R \$ 460$ milhões em obras suspensas. Estadão, São Paulo, 1 jun. 2014. Entrevista concedida a Laura Greenhalgh. Disponível em: <http:// educacao.estadao.com.br/noticias/geral,sao-r-460-milhoes-em-obras-suspensas,1503397>. Acesso em: 30 jul. 2014.

WANDERLEY, L. E. O que é universidade? São Paulo: Brasiliense, 1983. 